\title{
Association of Dietary Total Antioxidant Capacity and MC4R Polymorphisms in Metabolically Healthy and Unhealthy Overweight/Obese Women
}

maryam elhamkia ( $\sim$ eihamkiam@gmail.com )

Tehran University of Medical Sciences

Leila Setayesh

Tehran University of Medical Sciences

Habib Yarizadeh

Tehran University of Medical Sciences

Sara Pooyan

Tehran University of Medical Sciences

\section{Zahra Veysi}

Tehran University of Medical Sciences

Vajihe Aghamohammadi

Tehran University of Medical Sciences

Krista Casazza

Florida Gulf Coast University

Khadijeh Mirzaei

Tehran University of Medical Sciences

\section{Research Article}

Keywords: Diet, Melanocortin type 4 receptor (MC4R), Metabolically Healthy Obesity, Dietary Total Antioxidant Capacity, Karelis Criteria, gene

Posted Date: May 26th, 2021

DOl: https://doi.org/10.21203/rs.3.rs-456887/v1

License: (c) (i) This work is licensed under a Creative Commons Attribution 4.0 International License.

Read Full License 


\section{Abstract}

Background: $3-15 \%$ of people with obesity display a metabolically healthy phenotype. An inflammatory diet impairs metabolic signaling pathways and eliciting metabolic syndrome. The main purpose of this study was to investigate how the Dietary Total Antioxidant Capacity (DTAC) and the MC4R variants affect the metabolic health status in overweight and obese Iranian women.

Methods and results: This cross-sectional study was conducted on 237 overweight-obese Tehrani women with mean age of 36 years. The DTAC was calculated using the following indices: total reactive antioxidant potential (TRAP), Trolox equivalent antioxidant capacity (TEAC), and the ferric-reducing ability of plasma (FRAP). The Metabolic health was evaluated using the Karelis criteria. The MC4R genotypes were determined by the restriction fragment length polymorphism (PCR-RFLP) method.

Approximately $43 \%$ of participants were identified as Metabolically Unhealthy Obesity (MUO), $6 \%$ Metabolically Healthy Obesity (MHO) including $42.5 \%$ of the total had T/T genotype, $23.8 \%$ had the $\mathrm{C} / \mathrm{T}$ genotype, and $33.5 \%$ had the $\mathrm{C} / \mathrm{C}$ genotype $(P=0.05)$. In the $\mathrm{C} / \mathrm{C}$ genotype people $75 \%$ were unhealthy whereas it was lower in $\mathrm{T} / \mathrm{T}$ and $\mathrm{T} / \mathrm{C}$ genotype people. Further, The $\mathrm{C} / \mathrm{C}$ genotype with higher DTAC quartile had higher Karlis score than other DTAC quartile. A liner model test supported that the probability of $\mathrm{MHO}$ was significantly higher in subjects with the $\mathrm{T} / \mathrm{C}$ genotype $(\beta=-0.001,95 \% \mathrm{Cl}=-0.001-4.796 ; \mathrm{P} \leq$ $0.1)$.

Conclusions: Our results indicated that the $\mathrm{C} / \mathrm{C}$ genotype with higher DTAC had favorable lipid profile and were metabolically healthier. It is plausible that dietary modification targeting antioxidant intake may attenuate metabolic impairments associated with genetic predisposition.

\section{Introduction}

The global prevalence of obesity and its upcoming metabolic complications and chronic diseases such as insulin resistance, dyslipidemia, hypertension, inflammation, cardiovascular diseases (CVD), type 2 diabetes mellitus (DM2) continue to rise [1-3]. Interestingly, 3-15\% of people with obesity do not present diagnosed metabolic complications [4-6]. Although, people with obesity considered metabolically healthy have a higher risk of CVD compared to normal weight individuals without metabolic alterations, the risk appears less than metabolically unhealthy obese people [7-9]. It is suggested that a nutrigenomic factor or mechanism affording some protection against metabolic syndrome [10].

Rare mutations in the melanocortin-4 receptor (MC4R), the second SNPs for obesity, are relared with lower energy expenditure and more likely to experience hyperphagia. According to estimates, polymorphisms in this gene are responsible for $2.4-9 \%$ of significant obesity and has a tight interaction with environmental factors [11-13] There are also some variants in the MC4R gene, which may have preventive effects on obesity $[7,14]$. Several variants in the MC4R gene have been identified which rs 17782313 polymorphism $(T / C)$ is one of those frequently described [15-21]. A higher BMI and energy intake in people with the common SNP rs17782313 near MC4R gene have also been observed [22-24]. Further, an association of 
rs17782313 polymorphism (T/C) with increased risk of obesity among subgroups of Europeans and East Asians, adults and children has been well reported $[8,22,25]$.

The interaction of the MC4R polymorphisms and metabolism may be moderated by the adaptive response to oxidative stress. Oxidative stress represents an integral component of metabolic complications. Dietary total antioxidant capacity (DTAC) is an reliable indicator of diet quality and is typically used to estimate the cumulative effect of antioxidants in the diet overall [26]. It can also provide insight into synergistic effects that may exist between diverse antioxidants in a mixed diet $[14,15]$. The overproduction of reactive oxygen species may impair insulin signaling pathways and lead to endothelial damage. This causes insulin resistance and promotes acceleration of the atherogenic processes underlying metabolic syndrome, obesity, type 2 diabetes and CVD $[18,19]$. The relationship between DTAC and MC4R polymorphism has been investigated in limited studies mostly with healthy people. To our knowledge, there have been few human based studies in Middle East countries with different genotype structure and diet pattern, evaluating this relationship regarding metabolic health status. As high incidence of metabolic disorders continue to burden the region, the aim of this cross-sectional study was to assess the interaction between DTAC and MC4R among overweight and obese Iranian women with regard to their metabolic health status.

\section{Method}

\subsection{Study population}

In this cross-sectional study, 218 out of 288 healthy women with overweight and obesity who were referred to community health centers of Tehran university of medical science were randomly selected based on the following inclusion criteria: 1) body mass index (BMI) 25-40 kg.m2 - 2) aged 18-50 years old. The primary exclusion criteria included the following:1) menopause 2) pregnancy 3) cardiovascular diseases 4) diabetes 5) Cancer 6) kidney disease 7) thyroid disease 8) acute or chronic diseases 9) use of dietary supplements for weight loss 10) follow up diet during the past year 11) use of lipid lowering drugs 12) use of blood glucose lowering drugs. More over, participants who did not complete more than 35 items of the food frequency questionnaire and those who reported total daily energy intakes $\leq 800$ or $\geq 4500 \mathrm{kcal} / \mathrm{d}$ were excluded. This study carried out in accordance with the recommendations of the ethics committee of institution (Ethical number IR.TUMS.VCR.REC.1398.619) with written informed consent from all participants .

\subsection{Anthropometric assessment}

For each participant, the height, the weight, waist, and hip circumferences were measured. These measurements were made in compliance with WHO recommendations and the assessments were performed by an experience nutritionist. Participants were weighed without shoes and in minimal clothing on a solar digital scale recorded to the last $0.2 \mathrm{~kg}$. The standing height was measured on a free-standing portable height meter with a precision of $0.5 \mathrm{~cm}$ without shoes. BMI was calculated by weight $(\mathrm{kg}) / \mathrm{height}$ (m) squared [10]. 


\subsection{Dietary assessment and DTAC evaluation}

Detailed dietary information was obtained through the use of the validated semi quantitative food frequency questionnaire (FFQ) [27]. The FFQ includes 147 items with a standard serving size commonly consumed by Iranians. The reported frequency for each food item was then converted to a daily intake. The nutrient content of foods were computed by the Nutritionist 4 software based on United States Department of Agriculture (USDA) food composition table modified for Iranian foods. DTAC was calculated using the following indices: total reactive antioxidant potential (TRAP), Trolox equivalent antioxidant capacity (TEAC), and the ferric-reducing ability of plasma (FRAP).Since no databases were available to calculate the quantity of antioxidants in Iranian foods, given the available resources, we chose databases that contained most of the foods that are consumed by the Iranian population. TRAP and TEAC values were obtained from published databases for Italian foods. For FRAP, we used a database developed by Halvorsen et al. Total antioxidant capacity values for each food item in the FFQ were matched to an equivalent food in each of the databases. If any food was not directly matched with a corresponding food in a database, a proxy estimation was used based on the mean value of a similar food or the value of a raw food as a substitute for the cooked food [19, 21]. DTAC for every participant was obtained by multiplying the daily intake of each selected food item by its corresponding antioxidant value per food portion and summing the final values. Antioxidants from supplements were not included in the calculation of DTAC reported as micromole of Trolox Equivalents per day ( $\mu \mathrm{mol}$ TE/day).

\subsection{Biochemical analysis}

Venous blood was drawn at 8:00 AM to avoid variations due to circadian rhythm and after a fast equal to or>12 h. Samples were collected in two tubes, one containing sodium citrate and the other without anticoagulant centrifuged at $3000 \mathrm{rpm}$ for $15 \mathrm{~min}$ at $4{ }^{\circ} \mathrm{C}$, and aliquots of plasma and serum were prepared for testing. Glucose, total cholesterol, HDL-C, and triglycerides levels were determined by the semiautomatic chemical analyzer Ekem KontroLab. LDL-C serum concentration was calculated with Fried Ewald's formula. Insulin resistance was evaluated through homeostasis model assessment : HOMA$\mathrm{IR}=$ insulin $(\mathrm{mU} / \mathrm{mL}) \times$ fasting glucose $(\mathrm{mmol} / \mathrm{L}) / 22.5[28]$.

\subsection{Definition of metabolically healthy and unhealthy phenotypes}

There are no general definition of metabolically healthy obesity (MHO).Throughout this paper, the MHO was described using adapted Karelis criteria. In the case of the Karelis criteria : total cholesterol $\leq 200$ $\mathrm{mg} / \mathrm{dL}$, triglycerides $\leq 150 \mathrm{mg} / \mathrm{dL}(\leq 1.7 \mathrm{mmol}$.L), high-density lipoprotein cholesterol (HDL_C) $\geq 50 \mathrm{mg} / \mathrm{dL}$ and no treatment, low-density lipoprotein cholesterol (LDL-C) $\leq 100 \mathrm{mg} / \mathrm{dL}$ and no treatment, and HOMAIR $\leq 2.8$; that $\geq 4$ positive score criteria defined as Metabolic Healthy. Thus, participants were classified into 4 groups according to metabolic health: Metabolically Healthy Over Weight (MHOW), Metabolically Unhealthy Over Weight (MUOW), Metabolically Healthy Obesity (MHO) and Metabolically Unhealthy Obesity $(\mathrm{MUO})[8,10]$.

\subsection{The Genotype determination}


The chromosome 9p21 rs17782313 SNP (genotypes C \&T) was genotyped by the polymerase chain reaction-restriction fragment length polymorphism (PCRRFLP) technique. The Genomic DNA was extracted from $200 \mathrm{~mL}$ of whole blood using the Mini Columns Type G kit manual (GeneAll, South Korea). The extracted DNA was used to assess two reported SNPs near MC4R gene, rs17782313 and rs17700633 SNPs. Polymerase chain reaction (PCR) was performed on the rs17782313 and rs17700633 SNPs using the following primers: forward primer 5AAGTTCTACCTACCATGTTCTTGG-3 and reverse primer 5TTCCCCCTGAAGCTTTTCTTGTCATTTTGAT-3. PCR was carried out on a total volume of $20 \mu \mathrm{L}$, containing $1 \mu \mathrm{l}$ extracted DNA, $0.5 \mu$ primers $F, 0.5 \mu$ l primers $\mathrm{R}, 10 \mu \mathrm{l}$ Permix (Amplicon, Germany), and 8 $\mu \mathrm{l}$ Distilled water, with the following conditions in a DNA thermocycler: 1- primary denaturation at $95^{\circ} \mathrm{C}$ for 2 min; 2- Thirty- five cycles of denaturation at $95^{\circ} \mathrm{C}$ for 30 seconds, annealing at $58^{\circ} \mathrm{C}$ for 30 seconds, extension at $72^{\circ} \mathrm{C}$ for 30 seconds; 3 - final extension at $72^{\circ} \mathrm{C}$ for $5 \mathrm{~min} ; 4$ - final step at $4^{\circ} \mathrm{C}$. The amplification protocol consisted of a primary denaturation step at $94^{\circ} \mathrm{C}$ for $5 \mathrm{~min}$, followed by 35 cycles of denaturation at $60^{\circ} \mathrm{C}$ for $1 \mathrm{~min}$, annealing at $94^{\circ} \mathrm{C}$ for $45 \mathrm{~s}$, and extension at $72^{\circ} \mathrm{C}$ for $1 \mathrm{~min}$, and final extension at $72^{\circ} \mathrm{C}$ for $10 \mathrm{~min}$. The digestion products were stained with ethidium bromide on a $2 \%$ agarose gel and imaged. $10 \%$ of the samples were directly sequenced for confirmation the PCR-RFLP results. The sequencing process performed using the ABI PRISM 3730 automated sequencer (Applied Biosystems, Foster City, CA, USA) [29]. Amplified DNA (7 $\mu$ l) was digested with $0.5 \mu$ l of BCIl restriction enzyme (Fermentase, Germany) at $56^{\circ} \mathrm{C}$ overnight. All products were visualized by agarose gel electrophoresis. Then, fragments containing three genotypes were distinguished: CC, CT, and TT.

\subsection{Statistical analyses}

Statistical analyses were performed using SPSS 20 (SPSS Inc., Chicago, IL, USA). Normal data distribution was determined using the Kolmogorov-Smirnov test. The ANOVA test and general linear model were used to assess differences in biochemical measurements and characteristics between groups. A general linear model adjusted for MC4R, DTACT as confounder effects was used. Coding of the SNPs was performed using an additive model. The study population characteristics are reported as mean \pm standard deviation (SD). The Statistical significance was defined as $p \leq 0.05$ for all analyses.

\section{Results}

The mean and standard deviation (SD) of age of the participants were $36.23 \pm 8.2$ years, range 18-50 years. The characteristics of participants are summarized in Table 1. Participants were $43 \%$ MUOB, $6.3 \%$ MHOB, 29.5\% MUOW and 20.6\% MHOW, according to Karelis criteria. In the C/C genotype people $75 \%$ were unhealthy where as it declined to $67.1 \%$ and $67.4 \%$ in $\mathrm{T} / \mathrm{T}$ and $\mathrm{T} / \mathrm{C}$ genotype people respectively. 
Table 1

Characteristics of the study participants

\begin{tabular}{|llll|}
\hline & Mean \pm SD & Min & Max \\
\hline $\mathrm{AGE}(\mathrm{y})$ & $36.23 \pm 8.22$ & 18 & 50 \\
\hline $\mathrm{BMI}(\mathrm{Kg} / \mathrm{m} 2)$ & $30.69 \pm 3.69$ & 25.00 & 40.70 \\
\hline $\mathrm{WHR}$ & $0.93 \pm 0.05$ & 0.81 & 1.08 \\
\hline $\mathrm{TG}(\mathrm{mg} / \mathrm{dL})$ & $120.94 \pm 68.69$ & 37.00 & 512.00 \\
\hline $\mathrm{HDL}(\mathrm{mg} / \mathrm{dL})$ & $46.36 \pm 10.58$ & 18.00 & 82.00 \\
\hline $\mathrm{LDL}(\mathrm{mg} / \mathrm{dL})$ & $94.42 \pm 23.81$ & 34.00 & 156.00 \\
\hline Insulin( $\mu \mathrm{IU} / \mathrm{mL})$ & $15.56 \pm 6.02$ & 6.67 & 65.89 \\
\hline $\mathrm{HOMA}$ INDEX & $3.40 \pm 1.52$ & 1.29 & 16.59 \\
\hline $\begin{array}{l}\text { DTAC } \\
\text { (mmol TE/100 g) }\end{array}$ & $1167.28 \pm 764.66$ & 9.11 & 4179.96 \\
\hline $\begin{array}{l}\text { Abbreviations: SD, standard deviation; Min, minimum; Max, maximum; BMI, body mass index; } \mathrm{HDL} \text {, } \\
\text { high-density lipoprotein cholesterol; LDL, low-density lipoprotein cholesterol; } \text { HOMA, homeostatic } \\
\text { model assessment; TG,triglycerides; DTAC, Dietary total antioxidant capacity }\end{array}$ & \\
\hline
\end{tabular}

There was a significant difference between groups in metabolic health status. All Subjects in the metabolically unhealthy groups had higher BMI, TG, LDL-C, HOMA-Index, insulin and lower HDL-C than those in the metabolically healthy groups significantly $(P \leq 0.05)$ (Table 2$)$. 
Table 2

The Metabolic characteristics of healthy and unhealthy groups

\begin{tabular}{|c|c|c|c|c|c|}
\hline BMI & & MH-OW & MU-OW & $\mathrm{MHO}$ & MUO \\
\hline \multirow[t]{2}{*}{$(\mathrm{Kg} / \mathrm{m} 2)$} & $\begin{array}{l}\text { Mean } \pm \\
\text { SD }\end{array}$ & $27.55 \pm 1.60$ & $27.72 \pm 1.36$ & $32.42 \pm 2.80$ & $33.33 \pm 2.69$ \\
\hline & $p$-value & $\leq 0.05$ & & & \\
\hline \multirow[t]{2}{*}{$\mathrm{HDL}(\mathrm{mg} / \mathrm{dL})$} & $\begin{array}{l}\text { Mean } \pm \\
\text { SD }\end{array}$ & $\begin{array}{l}80.20 \pm \\
26.50\end{array}$ & $117.05 \pm 49.38$ & $80.00 \pm 20.84$ & $149.13 \pm 84.10$ \\
\hline & $p$-value & $\leq 0.05$ & & & \\
\hline \multirow[t]{2}{*}{$\mathrm{TG}(\mathrm{mg} / \mathrm{dL})$} & $\begin{array}{l}\text { Mean } \pm \\
\text { SD }\end{array}$ & $51.69 \pm 9.97$ & $43.98 \pm 8.05$ & $53.00 \pm 7.33$ & $44.47 \pm 11.60$ \\
\hline & $p$-value & $\leq 0.05$ & & & \\
\hline \multirow[t]{2}{*}{ LDL(mg/dL) } & $\begin{array}{l}\text { Mean } \pm \\
\text { SD }\end{array}$ & $\begin{array}{l}86.10 \pm \\
19.84\end{array}$ & $95.97 \pm 22.93$ & $81.75 \pm 18.77$ & $99.73 \pm 25.06$ \\
\hline & $p$-value & $\leq 0.05$ & & & \\
\hline \multirow[t]{2}{*}{ INSULIN $(\mu \mathrm{IU} / \mathrm{mL})$} & $\begin{array}{l}\text { Mean } \pm \\
\text { SD }\end{array}$ & $11.73 \pm 3.62$ & $15.92 \pm 4.68$ & $12.33 \pm 3.92$ & $17.67 \pm 7.13$ \\
\hline & $p$-value & $\leq 0.05$ & & & \\
\hline \multirow[t]{2}{*}{ HOMA INDEX } & $\begin{array}{l}\text { Mean } \pm \\
\text { SD }\end{array}$ & $2.45 \pm 0.85$ & $3.38 \pm 1.03$ & $2.52 \pm 0.89$ & $3.96 \pm 1.84$ \\
\hline & $p$-value & $\leq 0.05$ & & & \\
\hline \multicolumn{6}{|c|}{$\begin{array}{l}\text { Abbreviations: SD, standard deviation; MH-OWBMI, body mass index; HDL, high-density lipoprotein } \\
\text { cholesterol; LDL,low- } \\
\text { densitylipoproteincholesterol;HOMA,homeostaticmodelassessment;TG,triglycerides;MH-OW, } \\
\text { metabolically healthy overweight; MU-OW, metabolically unhealthy overweight; MHO, metabolically } \\
\text { healthy obesity; MUO, metabolically healthy overweight, ANOVA test (P } \leq 0.05)\end{array}$} \\
\hline
\end{tabular}

Table 3 represented that the mean DTAC was $1167.28 \mathrm{mEq}$ with \pm SD 764.66. The TG, LDL, HOMA-INDEX values had inverse relation to DTAC values, albeit insignificant $(P \leq 0.05)$ (Table 3$)$. 
Table 3

The Mean \& \pm SD of metabolic values in DTAC tertile groups

\begin{tabular}{|c|c|c|c|}
\hline Variables & DTAC tertile & Mean \pm SD & P-value \\
\hline \multirow{4}{*}{$\begin{array}{l}\text { BMI } \\
(\mathrm{Kg} / \mathrm{m} 2)\end{array}$} & low & $30.32 \pm 3.59$ & \multirow[t]{4}{*}{0.61} \\
\hline & median & $30.87 \pm 3.42$ & \\
\hline & high & $30.68 \pm 3.92$ & \\
\hline & Total & $30.62 \pm 3.64$ & \\
\hline \multirow[t]{4}{*}{$\mathrm{TG}(\mathrm{mg} / \mathrm{dL})$} & low & $122.86 \pm 72.58$ & \multirow[t]{4}{*}{0.80} \\
\hline & median & $117.78 \pm 73.38$ & \\
\hline & high & $115.12 \pm 67.06$ & \\
\hline & Total & $118.51 \pm 70.67$ & \\
\hline \multirow[t]{4}{*}{$\mathrm{HDL}(\mathrm{mg} / \mathrm{dL})$} & low & $47.17 \pm 10.52$ & \multirow[t]{4}{*}{0.75} \\
\hline & median & $45.92 \pm 10.77$ & \\
\hline & high & $47.12 \pm 11.73$ & \\
\hline & Total & $46.75 \pm 11.00$ & \\
\hline \multirow[t]{4}{*}{$\mathrm{LDL}(\mathrm{mg} / \mathrm{dL})$} & low & $93.45 \pm 24.74$ & \multirow[t]{4}{*}{0.97} \\
\hline & median & $92.75 \pm 22.51$ & \\
\hline & high & $92.64 \pm 23.04$ & \\
\hline & Total & $92.94 \pm 23.33$ & \\
\hline \multirow{4}{*}{$\begin{array}{l}\text { INSULIN } \\
(\mu \mathrm{IU} / \mathrm{mL})\end{array}$} & low & $15.76 \pm 5.07$ & \multirow[t]{4}{*}{0.88} \\
\hline & median & $15.21 \pm 4.69$ & \\
\hline & high & $15.45 \pm 8.38$ & \\
\hline & Total & $15.48 \pm 6.32$ & \\
\hline \multirow[t]{4}{*}{ HOMA-INDEX } & low & $3.43 \pm 1.20$ & \multirow[t]{4}{*}{0.90} \\
\hline & meadian & $3.31 \pm 1.31$ & \\
\hline & high & $3.37 \pm 2.14$ & \\
\hline & Total & $3.37 \pm 1.618$ & \\
\hline \multicolumn{4}{|c|}{ Data presented as SD, standard deviation; } \\
\hline \multicolumn{4}{|c|}{$\begin{array}{l}\text { BMI, body mass index; HDL, high-density lipoprotein cholesterol; LDL, low-density lipoprotein } \\
\text { cholesterol; HOMA, homeostatic model assessment; IR, insulin resistance; TG, triglycerides; DTAC, } \\
\text { Dietary total antioxidant capacity, ANOVA test (P } \leq 0.05)\end{array}$} \\
\hline
\end{tabular}


Furthermore, the T/T genotype was identified in $42.5 \%, 23.8 \%$ the $\mathrm{C} / \mathrm{T}$ genotype, and $33.5 \%$ the $\mathrm{C} / \mathrm{C}$ genotype. The $\mathrm{C} / \mathrm{C}$ genotype with higher DTAC quartile had higher Karlis score than other DTAC quartile. The T/C genotype had higher TG, LDL-C and HOMA-INDEX but not statistically different from other genotypes. Although, meaningful correlation was observed between this genotype and insulin $(P \leq 0.05)$ and HOMA-INDEX $(\mathrm{P} \leq 0.05)$ (Table 4).

Table 4

The Mean \& \pm SD of variables in MC4R rs17782313 Polymorphism groups

\begin{tabular}{|c|c|c|c|}
\hline Variables & \multicolumn{2}{|c|}{ polymorphism } & P-value \\
\hline \multirow{3}{*}{$\begin{array}{l}\text { BMI } \\
(\mathrm{Kg} / \mathrm{m} 2)\end{array}$} & TT & $30.74 \pm 3.65$ & \multirow[t]{3}{*}{0.91} \\
\hline & $\mathrm{TC}$ & $30.51 \pm 3.61$ & \\
\hline & $\mathrm{CC}$ & $30.74 \pm 3.70$ & \\
\hline \multirow[t]{3}{*}{$\mathrm{TG}(\mathrm{mg} / \mathrm{dL})$} & TT & $125.09 \pm 81.36$ & \multirow[t]{3}{*}{0.33} \\
\hline & $\mathrm{TC}$ & $126.60 \pm 68.60$ & \\
\hline & $\mathrm{CC}$ & $110.71 \pm 55.15$ & \\
\hline \multirow[t]{3}{*}{$\mathrm{HDL}(\mathrm{mg} / \mathrm{dL})$} & $\mathrm{TT}$ & $45.34 \pm 10.34$ & \multirow[t]{3}{*}{0.33} \\
\hline & $\mathrm{TC}$ & $47.30 \pm 11.32$ & \\
\hline & $\mathrm{CC}$ & $47.45 \pm 10.96$ & \\
\hline \multirow[t]{3}{*}{$\mathrm{LDL}(\mathrm{mg} / \mathrm{dL})$} & TT & $91.36 \pm 23.04$ & \multirow[t]{3}{*}{0.34} \\
\hline & $\mathrm{TC}$ & $97.00 \pm 26.07$ & \\
\hline & $\mathrm{CC}$ & $95.31 \pm 24.93$ & \\
\hline \multirow{3}{*}{$\begin{array}{l}\text { INSULIN } \\
(\mu \mathrm{IU} / \mathrm{mL})\end{array}$} & TT & $14.63 \pm 4.58$ & \multirow[t]{3}{*}{0.04} \\
\hline & $\mathrm{TC}$ & $17.25 \pm 9.21$ & \\
\hline & $\mathrm{CC}$ & $15.65 \pm 4.96$ & \\
\hline \multirow[t]{3}{*}{ HOMA-INDEX } & $\mathrm{TT}$ & $3.14 \pm 1.08$ & \multirow[t]{3}{*}{0.02} \\
\hline & $\mathrm{TC}$ & $3.88 \pm 2.42$ & \\
\hline & $\mathrm{CC}$ & $3.37 \pm 1.25$ & \\
\hline \multicolumn{4}{|c|}{ Data presented in SD, standard deviation; } \\
\hline \multicolumn{4}{|c|}{$\begin{array}{l}\text { BMI, body mass index; HDL-C, high-density lipoprotein cholesterol; LDL-C, low-density lipoprotein } \\
\text { cholesterol; HOMA, homeostatic model assessment; IR, insulin resistance; TG, triglycerides; DTAC, } \\
\text { Dietary total antioxidant capacity; MC4R Gene, melanocortin-4 receptor polymorphism, ANOVA test }(F \\
\leq 0.05)\end{array}$} \\
\hline
\end{tabular}


To assess the interaction between particular polymorphisms and the MUO and $\mathrm{MHO}$, a liner model test was applied (Table 5). The test revealed that the probability of being $\mathrm{MHO}$ was lower in subjects with the $\mathrm{C} / \mathrm{C}$ genotype than two other genotypes. The test value was statistically significant $(\beta=0,95 \% \mathrm{Cl}: 0.000-$ $0.001 ; P \leq 0.05)$. Interestingly, it was observed that $C / C$ genotype with higher DTAC were metabolically healthier. In contrast, T/C genotype with lower DTAC values were metabolically healthier (Fig. 1).No significant correlation detected between the T/T genotype and DTAC level.

Table 5

The Interaction between MC4R Gene Polymorphism and DTAC

\begin{tabular}{|lllll|}
\hline Independent Variables & B & Std. Error & Cl & P-Value \\
\hline MC4R CC* DTAC & 0.00 & 0.00 & $0.00-0.00$ & 0.05 \\
\hline MC4R TT* DTAC & 0.00 & 0.00 & $0.00-0.00$ & 0.28 \\
\hline MC4R TC* DTAC & 0.00 & 0.00 & $0.00-4.79$ & 0.05 \\
\hline Liner model test, reference = MC4R CC & & \\
\hline Dependent variable: Karlis & & \\
\hline For interactions $p<0.1$ was considered significant. \\
\hline a. set to zero because this parameter is redundant \\
\hline b. maximum likelihood estimate. \\
\hline
\end{tabular}

\section{Discussion}

This cross-sectional study investigated how the DTAC and MC4R gene variants were related to being $\mathrm{MHO} / \mathrm{MUO}$ in overweight and obese women. Interactions between genetic and environmental factors play an important part in the metabolic health status and obesity. Our results showed that a significant correlation was between the DTAC and the MC4R SNPs and the MHO. MUOW-OB diagnosed on the basis of the Karelis criteria was observed in $67.4 \%$ of these overweight-obese women. It was slightly more common in the subgroup with the $\mathrm{C} / \mathrm{C}$ genotype $(75 \%)$. The liner model test showed that the $\mathrm{C}$ allele raises the risk of metabolically unhealthy significantly. For the first time, this study provided evidence for a significant relation between the MC4R gene and the DTAC level. The $\mathrm{C} / \mathrm{C}$ genotype subjects with higher DTAC had favorable lipid profile and were metabolically healthier. Conversely, T/C genotype subjects with lower DTAC values were metabolically healthier. These results supported the interaction was found between the T/C genotype and the metabolism in some previous studies[5].

$\mathrm{MHO} / \mathrm{OW}$ incidence in this study was similar previous studies $[4,8,30,31]$. The recent Hosseinpanah cohort study showed that $26.9 \%$ of male and $39.4 \%$ of female Iranian people were MHO [31].

Pervious studies have demonstrated that metabolically healthy obese people (MHO) have a lower risk of CVD compared to the MUO population [7, 8]. Although the causes of this metabolic alterations are still not 
clearly understood, evidence suggests that interactions between the genetic and life style factors including diet can influence such phenotypes in various population.

The MC4R SNPs prevalence in the Iranian ow/ob women was similar to the results of Mollahosseini et al study with the prevalence of the $\mathrm{C} / \mathrm{C}$ allele $52.85 \%$ [3]. Furthermore, we observed a close connection between (SNP) of this gene and increased BMI. In line with our findings, previous studies showed that the $\mathrm{C} / \mathrm{C}$ allele carriers' BMI was higher by $0.2 \mathrm{~kg} \cdot \mathrm{m}^{2}$ on average $[5,22,23]$. German authors reported Comparable results, who claimed that the presence of the $\mathrm{C} / \mathrm{C}$ allele entailed a considerably higher BMI. Even though we were unable to demonstrate a significant correlation between the DTAC values and TG, LDL, HOMA-INDEX values, earlier researches revealed an inverse relationship between these factors. This apparent lack of correlation could be attributed to hard to control entity of the DTAC and method of study.

Previous investigations revealed that higher DTAC positively affected obesity related disorders [8, 21]. Mousavizadeh's study suggested that the healthy diet interacts with MC4RSNP (rs17782313) which decrease the risk of general obesity in C-allele carriers [24].

In another similar study, high DTAC were significantly associated with a reduced odds ratio for the prevalence of chronic diseases and metabolic syndrome components [32]. Besides, the findings of longitudinal Tehran Lipid and Glucose Study showed that higher DTAC were positively associated with a lower occurrence of metabolic complications, hence being healthy[33]. The European Prospective Investigation into Cancer and Nutrition study pointed out the DTAC might play an essential role in reducing the risk of diabetes in women [34]. MC4R SNPs changes metabolic profile through uncertain mechanisms. Their phenotypic expression is affected by environmental factors, such as quantitative and qualitative composition of diet [13].

In line with previous studies, a statically significant association between MC4R genotype and Insulin and HOMA-INDEX was observed[1, 4, 8]. This to some extent confirms that insulin resistance may be the mechanism through which the MC4R polymorphisms affect metabolism leading to be metabolically healthy or unhealthy obese. In other word, HOMA-INDEX could likely be important predictor in general population $[4,35,36]$. Achilike et al. study suggested that lipid profile and insulin resistance are two key factors that predict the development of metabolically healthy or unhealthy obesity [35].

The main strengths of this study include assessment of MC4R SNPs regarding Metabolic Health OW-OB in Iranian women (A Middle East countries). The first limitation of the study was small sample that could not examine the exact odds ratios. Other limitation were monogender and cross-sectional method of study. Hence, it is suggested that other scientists perform similar studies with larger sample sizes and the case-control method. Beside, we did not have normal weight subjects for better comparison.

In Conclusion, Our study supported that higher dietary antioxidant intake have favorable effects on metabolic indexes in the $\mathrm{C} / \mathrm{C}$ genotype $\mathrm{MHO}$ people. Therefore, we could suggest that the encouragement of lifestyle modification including the consumption of antioxidant rich diet, is an important factor in nutritional interventions aimed at preventing metabolic complications. Furthermore, our results revealed 
that insulin resistance might be the mechanism through which the MC4R polymorphisms affect metabolism. HOMA-INDEX could likely be used as predictor of being MHO or MUO in investigations.

\section{Declarations}

Funding This study was supported by a Tehran University of Medical Sciences Grant) Grant Ids: 95-04161-33833, 97-03-161-41144, 97-02-161-38999. (

Conflicts of interest/Competing interests The authors declare that they have no conflict of interest.

Availability of data and material " applicable"

Code availability " applicable"

Authors' contributions [Khadijeh Mirzaei], Formal analysis and investigation: [Habib Yarizadeh], Writing original draft preparation: [Maryam ElhamKia]; Writing - review and editing: [Krista Casazza , Leila Setayesh, Maryam ElhamKia], Supervision: [khadijeh mirzaei], Methodology: [Zahra Veisy, Vajihe Aghamohammadi, Sara Pooyan]

Ethics approval Ethical number IR.TUMS.VCR.REC.1398.619

Consent to participate " applicable"

Consent for publication " applicable"

Acknowledgement: The authors are grateful to participants in the study for their contribution. This study was supported by a Tehran University of Medical Sciences Grant (Grant Ids: 95-04-161-33833, 97-03-16141144, 97-02-161-38999).

\section{References}

1. Gonçalves CG, Glade MJ, Meguid MM (2016) Metabolically healthy obese individuals: Key protective factors. Nutrition (Burbank, Los Angeles County. Calif) 32:14-20

2. Hamer M, Stamatakis E (2012) Metabolically healthy obesity and risk of all-cause and cardiovascular disease mortality. J Clin Endocrinol Metab 97:2482-2488

3. Mollahosseini M, Rahimi MH, Yekaninejad MS, Maghbooli Z, Mirzaei K. Dietary patterns interact with chromosome 9p21 rs1333048 polymorphism on the risk of obesity and cardiovascular risk factors in apparently healthy Tehrani adults. European journal of nutrition. 2019/01/03 ed2020. p. 35-43

4. Basurto L, Sanchez L, Diaz A, Valle M, Robledo A, Martinez-Murillo C (2019) Differences between metabolically healthy and unhealthy obesity in PAl-1 level: Fibrinolysis, body size phenotypes and metabolism. Thromb Res 180:110-114 
5. Gao L, Wang L, Yang H, Pan H, Gong F, Zhu H (2019) MC4R Single Nucleotide Polymorphisms Were Associated with Metabolically Healthy and Unhealthy Obesity in Chinese Northern Han Populations. International journal of endocrinology 2019:4328909

6. van Vliet-Ostaptchouk JV, Nuotio ML, Slagter SN, Doiron D, Fischer K, Foco L et al (2014) The prevalence of metabolic syndrome and metabolically healthy obesity in Europe: a collaborative analysis of ten large cohort studies. BMC endocrine disorders 14:9

7. Alberti KG, Eckel RH, Grundy SM, Zimmet PZ, Cleeman JI, Donato KA et al. Harmonizing the metabolic syndrome: a joint interim statement of the International Diabetes Federation Task Force on Epidemiology and Prevention; National Heart, Lung, and Blood Institute; American Heart Association; World Heart Federation; International Atherosclerosis Society; and International Association for the Study of Obesity. Circulation. 2009;120:1640-5

8. Hinnouho GM, Czernichow S, Dugravot A, Batty GD, Kivimaki M, Singh-Manoux A (2013) Metabolically healthy obesity and risk of mortality: does the definition of metabolic health matter? Diabetes Care 36:2294-2300

9. Iacobini C, Pugliese G, Blasetti Fantauzzi C, Federici M, Menini S (2019) Metabolically healthy versus metabolically unhealthy obesity. Metab Clin Exp 92:51-60

10. Ramos-Lopez O, Riezu-Boj JI, Milagro FI, Cuervo M, Goni L, Martinez JA (2019) Genetic and nongenetic factors explaining metabolically healthy and unhealthy phenotypes in participants with excessive adiposity: relevance for personalized nutrition. Therapeutic advances in endocrinology metabolism 10:2042018819877303

11. Xi B, Chandak GR, Shen Y, Wang Q, Zhou D (2012) Association between common polymorphism near the MC4R gene and obesity risk: a systematic review and meta-analysis. PloS one 7:e45731

12. Gilardini L, Zambon A, Soranna D, Croci M, Invitti C (2018) Predictors of the transition from metabolically healthy obesity to unhealthy obesity. Eating weight disorders: EWD 23:739-744

13. Manriquez V, Aviles J, Salazar L, Saavedra N, Seron P, Lanas F et al. Polymorphisms in Genes Involved in the Leptin-Melanocortin Pathway are Associated with Obesity-Related Cardiometabolic Alterations in a Southern Chilean Population. Molecular diagnosis \& therapy. 2018;22:101 - 13

14. Adan RA, Tiesjema B, Hillebrand JJ, la Fleur SE, Kas MJ, de Krom M (2006) The MC4 receptor and control of appetite. Br J Pharmacol 149:815-827

15. Zujko ME, Waśkiewicz A, Witkowska AM, Szcześniewska D, Zdrojewski T, Kozakiewicz K et al. Dietary Total Antioxidant Capacity and Dietary Polyphenol Intake and Prevalence of Metabolic Syndrome in Polish Adults: A Nationwide Study. Oxidative medicine and cellular longevity. 2018;2018:7487816

16. Sheikhansari G, Soltani-Zangbar MS, Pourmoghadam Z, Kamrani A, Azizi R, Aghebati-Maleki L et al. Oxidative stress, inflammatory settings, and microRNA regulation in the recurrent implantation failure patients with metabolic syndrome. American journal of reproductive immunology (New York, NY: 1989). 2019;82:e13170

17. Mozaffari H, Daneshzad E, Larijani B, Surkan PJ, Azadbakht L. Association of dietary total antioxidant capacity to anthropometry in healthy women: A cross-sectional study. Nutrition (Burbank, 
Los Angeles County, Calif). 2020;69:110577

18. Mohammadabadi FVZ, Hosseini SM, Aryaie M, Eshghinia S 1:23 - 7. Assessment of Insulin Resistance with Two Methods: HOMA-IR and TyG Index in Iranian Obese Women. Iran J Diab Obes. $2014623-7$

19. Lim J, Kim J, Koo SH, Kwon GC (2019) Comparison of triglyceride glucose index, and related parameters to predict insulin resistance in Korean adults: An analysis of the 2007-2010 Korean National Health and Nutrition Examination Survey. PloS one 14:e0212963

20. Brodowski J, Szkup M, Jurczak A, Wieder-Huszla S, Brodowska A, Laszczyńska M et al (2017) Searching for the relationship between the parameters of metabolic syndrome and the $\mathrm{rs} 17782313$ $(T>C)$ polymorphism of the MC4R gene in postmenopausal women. Clin Interv Aging 12:549-555

21. Aghamohammadi V, Sajjadi SF, Jarrahi F, Abdollahi A, Mirzaei K (2019) The association between total antioxidant capacity and resting metabolic rate (RMR) / respiratory quotient (RQ) in overweight and obese woman. Diabetes metabolic syndrome 13:2763-2767

22. Qi L, Kraft P, Hunter DJ, Hu FB (2008) The common obesity variant near MC4R gene is associated with higher intakes of total energy and dietary fat, weight change and diabetes risk in women. Human molecular genetics 17:3502-3508

23. Young EH, Wareham NJ, Farooqi S, Hinney A, Hebebrand J, Scherag A et al The V103I polymorphism of the MC4R gene and obesity: population based studies and meta-analysis of 29563 individuals. International journal of obesity (2005) 2007;31:1437-41

24. Mousavizadeh Z, Hosseini-Esfahani F, Javadi A, Daneshpour MS, Akbarzadeh M, Javadi M et al (2020) The interaction between dietary patterns and melanocortin-4 receptor polymorphisms in relation to obesity phenotypes. Obesity Research Clinical Practice 14:249-256

25. Loos RJ, Lindgren CM, Li S, Wheeler E, Zhao JH, Prokopenko I et al (2008) Common variants near MC4R are associated with fat mass, weight and risk of obesity. Nat Genet 40:768-775

26. Salehi-Sahlabadi AMA, Elhamkia M, Farahmand F, Jabbari M, Hekmatdoost A (2020) e00XXX Dietary Total Antioxidant Capacity and Risk of Non-Alcoholic Fatty Liver Disease: A Case-Control Study. J Res Health Sci 20(X):e00XXX

27. Mirmiran P, Esfahani FH, Mehrabi Y, Hedayati M, Azizi F (2010) Reliability and relative validity of an FFQ for nutrients in the Tehran lipid and glucose study. Public Health Nutr 13:654-662

28. Matthews DR, Hosker JP, Rudenski AS, Naylor BA, Treacher DF, Turner RC (1985) Homeostasis model assessment: insulin resistance and beta-cell function from fasting plasma glucose and insulin concentrations in man. Diabetologia 28:412-419

29. Pooyan S, Rahimi MH, Mollahosseini M, Khorrami-Nezhad L, Nasir Y, Maghbooli Z et al (2018) A High-Protein/Low-Fat Diet May Interact with Vitamin D-Binding Protein Gene Variants to Moderate the Risk of Depression in Apparently Healthy Adults. Lifestyle genomics 11:64-72

30. Latifi SM, Karandish M, Shahbazian H, Taha JM, Cheraghian B, Moradi M (2017) Prevalence of Metabolically Healthy Obesity (MHO) and its relation with incidence of metabolic syndrome, 
hypertension and type 2 Diabetes amongst individuals aged over 20 years in Ahvaz: A 5 Year cohort Study (2009-2014). Diabetes metabolic syndrome 11(Suppl 2):S1037-S10s40

31. Hosseinpanah F, Tasdighi E, Barzin M, Mahdavi M, Ghanbarian A, Valizadeh M et al (2020) The association between transition from metabolically healthy obesity to metabolic syndrome, and incidence of cardiovascular disease: Tehran lipid and glucose study. PloS one 15:e0239164

32. Sotoudeh G, Abshirini M, Bagheri F, Siassi F, Koohdani F, Aslany Z (2018) Higher dietary total antioxidant capacity is inversely related to prediabetes: A case-control study. Nutrition (Burbank, Los Angeles County. Calif) 46:20-25

33. Bahadoran Z, Golzarand M, Mirmiran P, Shiva N, Azizi F (2012) Dietary total antioxidant capacity and the occurrence of metabolic syndrome and its components after a 3-year follow-up in adults: Tehran Lipid and Glucose Study. Nutrition metabolism 9:70

34. Mancini FR, Affret A, Dow C, Balkau B, Bonnet F, Boutron-Ruault MC et al (2018) Dietary antioxidant capacity and risk of type 2 diabetes in the large prospective E3N-EPIC cohort. Diabetologia 61:308316

35. Achilike I, Hazuda HP, Fowler SP, Aung K, Lorenzo C. Predicting the development of the metabolically healthy obese phenotype. International journal of obesity (2005) 2015;39:228 - 34

36. Eshtiaghi R, Keihani S, Hosseinpanah F, Barzin M, Azizi F (2015) Natural course of metabolically healthy abdominal obese adults after 10 years of follow-up: the Tehran Lipid and Glucose Study. International Journal of Obesity 39:514-519

\section{Figures}

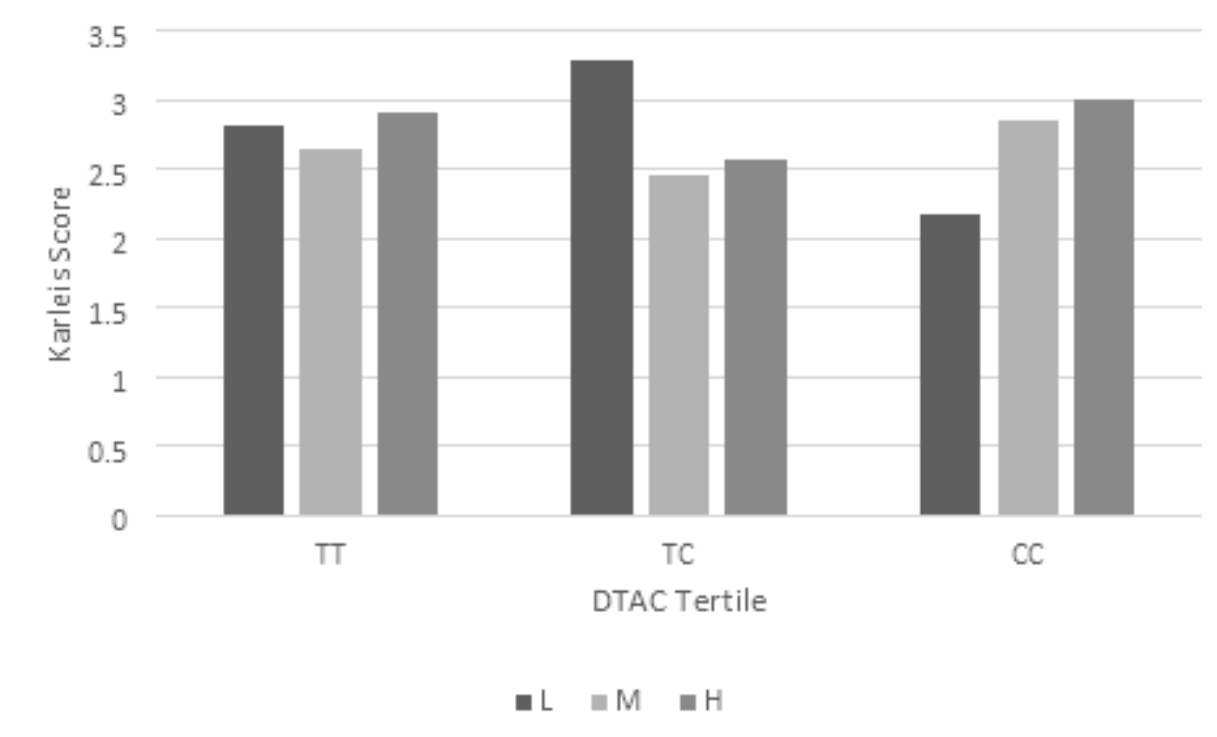

\section{Figure 1}

The association between Karelis scores and DTAC level tertile and the chromosome 9p21 rs1333048 SNP Polymorphisms L, low level of DTAC; $M$, median level of DTAC; $H$, high level of DTAC, P-value $\leq 0.05$. 